\title{
VIRUSES AND LYMPHOMAS
}

\section{HIV infection and lymphoma}

\author{
K L Grogg, R F Miller, A Dogan
}

J Clin Pathol 2007;60:1365-1372. doi: 10.1136/icp.2007.051953

The incidence of lymphoma in patients with HIV infection greatly exceeds that of the general population. The increased risk for lymphoma appears related to multiple factors, including the transforming properties of the retrovirus itself, the immunosuppression and cytokine dysregulation that results from the disease, and, most importantly, opportunistic infections with other lymphotrophic herpes viruses such as Epstein-Barr virus and human herpesvirus 8 . Histologically lymphomas fall into three groups: (1) those also occurring in immunocompetent patients; (2) those occurring more specifically in HIV-positive patients; and (3) those also occurring in patients with other forms of immunosuppression. Aggressive lymphomas account for the vast majority cases. They frequently present with advanced stage, bulky disease with high tumour burden and, typically, involve extranodal sites. Clinical outcome appears to be worse than in similar aggressive lymphomas in the general population. However, following the introduction of highly active antiretroviral therapy, the risk for developing lymphoma in the context of HIV infection has decreased and the clinical outcome has improved.

See end of article for authors' affiliations

Correspondence to: Professor Ahmet Dogan, Department of Laboratory Medicine and Pathology, Mayo Clinic, 200 First Street SW, Rochester MN 55905, USA; dogan. ahmet@mayo.edu

Accepted 9 August 2007
$\mathrm{F}$ ollowing the onset of the AIDS epidemic, it was soon recognised that the incidence of lymphoma in patients with HIV infection greatly exceeded that in the general population. The increased risk of lymphoma appears related to multiple factors, including the transforming properties of the retrovirus itself, the immunosuppression and cytokine dysregulation that results from the disease, and opportunistic infections with other lymphotrophic herpesviruses such as Epstein-Barr virus (EBV) and human herpesvirus 8 (HHV8). The heterogeneity in the pathogenesis of lymphoma in HIV-infected patients is reflected in the heterogeneous morphological subtypes.

The WHO classification of lymphoid neoplasms categorises the HIV-associated lymphomas into (1) those also occurring in immunocompetent patients, (2) those occurring more specifically in HIV-positive patients, and (3) those also occurring in patients with other forms of immunosuppression (box 1). ${ }^{1}$ Of these lymphomas, the majority are aggressive B-cell neoplasms that also occur in immunocompetent patients.

\section{EPIDEMIOLOGY AND CLINICAL FEATURES}

The relative risk of non-Hodgkin lymphoma is increased 60-200 fold in HIV-infected patients when compared with the general population. ${ }^{23}$ For certain subtypes of lymphoma, notably primary central nervous system (CNS) lymphoma, the risk for HIV-infected patients was increased 1000-fold over the general population during the early years of the AIDS epidemic. ${ }^{4}$ The widespread availability and uptake of highly active antiretroviral therapy (HAART) since 1996 has significantly reduced this risk. ${ }^{5-10}$ Although initial studies were inconsistent in showing this trend, it has since been shown that the risk reduction correlates with the improved CD4 counts that result from HAART. This effect is masked in patient populations where the availability or efficacy of HAART is compromised.

In addition to reducing the overall risk of lymphoma, HAART has had other effects on the epidemiologic characteristics of HIV-related lymphoma. A study linking the San Diego County Cancer Registry data with the San Diego County AIDS registry showed that the incidence of highly aggressive B-cell lymphomas such as immunoblastic diffuse large B-cell lymphoma (DLBCL) was reduced from $38 \%$ of HIV-associated non-Hodgkin lymphomas cases in the pre-HAART era to $19 \%$ in the post-HAART era. ${ }^{6}$ A similar decrease was seen in the proportion of primary CNS lymphoma, with

Box 1 Categories of HIV-associated lymphomas

(1) Lymphoma also occurring in immunocompetent patients

- Burkitt and Burkitt-like lymphoma

- Diffuse large B-cell lymphoma

- Centroblastic

- Immunoblastic (including primary CNS lymphoma)

- Extranodal marginal zone lymphoma of MALT type

- Peripheral T-cell lymphoma

- Classical Hodgkin lymphoma

(2) Lymphoma occurring more specifically in HIVpositive patients

- Primary effusion lymphoma

- Plasmablastic lymphoma of the oral cavity type

(3) Lymphoma also occurring in other immunodeficiency states

- Polymorphic B-cell lymphoma (PTLD-like) Adapted and modified from Raphael et al.' 

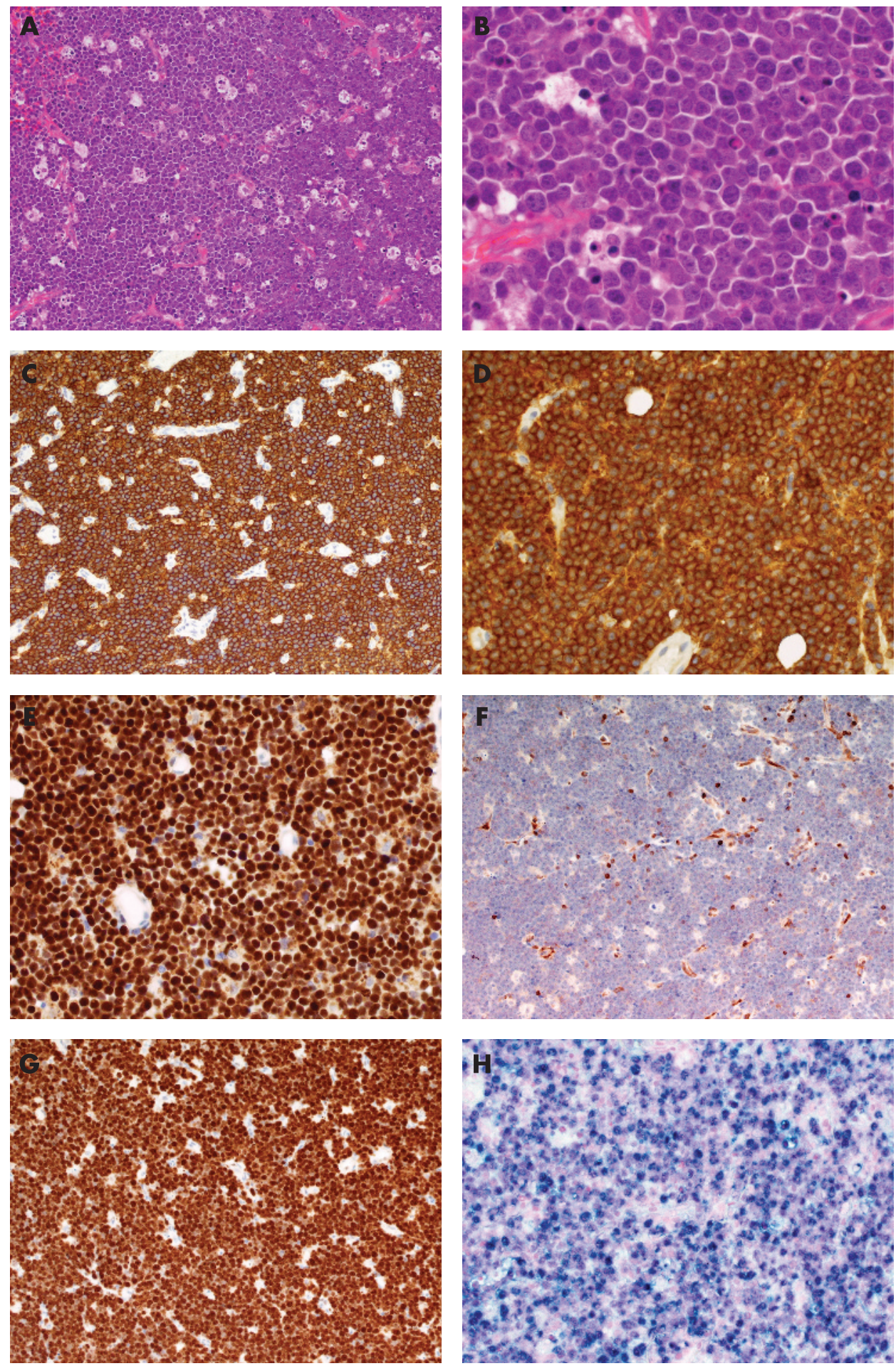

Figure 1 Histology and immunophenotype of Burkitt lymphoma in HIV infection. Low power view shows classical morphology with a starry star pattern (A). In the high power view the tumour is composed of intermediate sized cells with mild pleomorphism and 2-3 indistinct nucleoli (B). The cytoplasm has somewhat plasmacytoid characteristics (B). The neoplastic cells have the typical phenotype of Burkitt lymphoma expressing CD20 (C), CD10 (D) and BCL6 (E), but not BCL2 (F). They show virtually a $100 \%$ proliferation fraction with Ki67 staining (G). Approximately half of the cases are EpsteinBarr virus positive by in situ hybridisation for EBV-encoded RNA (H). a decrease from $28 \%$ to $17 \%$. By contrast, the proportion of centroblastic DLBCL increased from $21 \%$ to $44 \%$ of cases, and the proportion of Burkitt lymphoma increased from $4 \%$ to $9 \%$.

The observed changes in frequency of specific subtypes following the use of HAART can be explained by the dramatic decrease in the proportion of HIV-infected patients with profound immunosuppression. There is a significant relationship between the lymphoma subtype that develops in HIVpositive patients and the level of immunosuppression: Burkitt lymphoma and centroblastic DLBCL occur in patients with normal or slightly diminished CD4 counts; primary effusion lymphoma (PEL) and immunoblastic DLBCL (including primary CNS lymphoma) most often present later in the course of HIV infection in the context of marked immunodeficiency.

HIV infection also increases the risk of classical Hodgkin lymphoma, with a relative risk of 8-10-fold compared to the general population. ${ }^{11}$ The effect of HAART on the incidence of Hodgkin lymphoma (HL) is complex. While initial studies reported no decrease in HL risk following the introduction of HAART, more recent data suggest that there has been a slight increase in the risk of HL among HIV-positive patients. Additionally there is an apparent shift of sub-types with a higher proportion of the nodular sclerosis subtype compared to mixed cellularity or lymphocyte depleted subtypes. ${ }^{11}$ It has been 

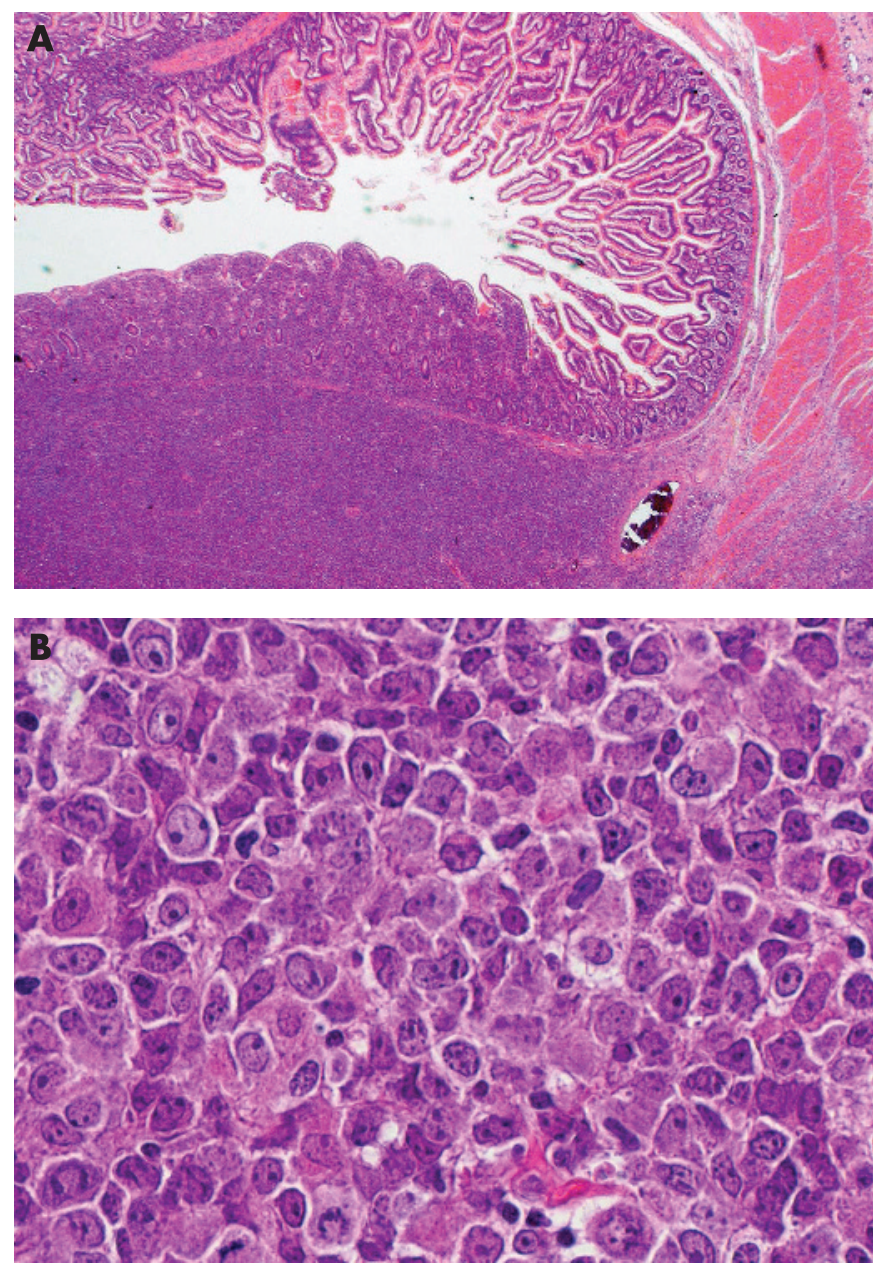

Figure 2 Histology of diffuse large B-cell lymphoma in HIV infection. Low power view showing an extranodal diffuse large B-cell lymphoma presenting with small intestinal involvement (A). The tumour is predominantly composed of centroblasts with occasional immunoblasts and is indistinguishable form centroblastic lymphoma occurring in immunocompetent patients (B).

speculated that the incidence of HL is actually lower in the context of severe immunodeficiency when compared with modest immune compromise, which is possibly related to the lack of necessary immune interaction between the ReedSternberg cells and the non-neoplastic inflammatory cells.

In HIV-infected patients, $80 \%$ of cases of non-Hodgkin lymphoma (NHL) present with advanced systemic disease and high levels of lactate dehydrogenase. There is a tendency for the lymphoma to involve extranodal sites, as with other immunosuppression-related lymphoma. Frequent sites of involvement include the CNS, gastrointestinal tract, liver and bone marrow. Other extranodal sites that are only rarely involved in HIV-negative patients, such as the anorectum and the heart, may also be affected.

\section{PATHOGENESIS OF HIV LYMPHOMA}

HIV is a lentivirus of the retrovirus family, and thus integrates into host chromosomal DNA using a DNA intermediate. It has been generally believed that integration of HIV is a random process, and therefore this process is not in itself oncogenic. ${ }^{12}$ In support of this theory is the fact that Southern blot analysis of HIV-associated lymphomas has failed to detect HIV sequences, ${ }^{13}$ with rare reports of clonal integration restricted to T-cell neoplasms. ${ }^{14}$ Although the neoplastic cells are not themselves infected with HIV in most cases, in vitro evidence suggests that HIV does have transforming properties. Laurence and Astin showed that HIV infection of B-cell lines derived from EBV-seropositive individuals led to B-cell immortalisation, dysregulation of $M Y C$, and activation of EBV. ${ }^{15}$ Certain HIV gene products, particularly Tat, have been implicated as potentially oncogenic in their role as transactivators of cellular genes, such as IL6 and IL10. ${ }^{16}$ Tat protein can more directly interfere with cell cycle control by interaction with the regulatory protein $\mathrm{Rb} 2 / \mathrm{pl} 30^{17}$ (as described in more detail below). This role of the Tat protein has been proposed as a significant factor in the pathogenesis of HIV-related Burkitt lymphoma. ${ }^{17}$

The predominant contribution of HIV to lymphoma pathogenesis is believed to be through indirect mechanisms. The increased risk for lymphoma among HIV-infected individuals appears related to multiple factors, including duration and degree of immunosuppression, induction of cytokines leading to B-cell proliferation, and opportunistic infections with oncogenic herpesviruses such as EBV and HHV8. ${ }^{13}$ EBV appears to play a prominent role, given its presence in $40-50 \%$ of HIVassociated lymphomas. ${ }^{1}$ The loss of EBV nuclear antigen 1 (EBNAl)-specific memory CD4 and CD8-positive T cells has been associated with progression to malignant lymphoma in AIDS patients. ${ }^{18}$ The deregulated and permissive immunological environment appears to allow accumulation of genetic alterations that lead to malignant transformation. The subtype of lymphoma that evolves appears predicated by the degree of immunosuppression, the presence or absence of coinfection, and the particular genetic abnormalities that develop.

\section{SPECIFIC CATEGORIES OF HIV-ASSOCIATED LYMPHOMA \\ Burkitt lymphoma}

Burkitt and Burkitt-like/atypical Burkitt lymphomas make up the largest group of HIV-associated non-Hodgkin lymphomas, comprising up to $35-50 \%$ of these neoplasms in some studies. ${ }^{19}$ In other studies, perhaps related to differences in pathological classification, Burkitt lymphoma is the second most common subtype after immunoblastic DLBCL. Classification of these lymphomas in the HIV setting follows the same diagnostic criteria as are used in the general patient population. That is, a diagnosis of Burkitt or Burkitt-like lymphoma requires a medium-sized CD10-positive B-cell population with a high proliferative rate and demonstration of a translocation involving the $M Y C$ gene. ${ }^{1}$ Peripheral blood involvement is less common in HIV-infected patients compared to HIV-negative patients with Burkitt lymphoma, although it can occur ${ }^{19} 20$; when present, circulating neoplastic cells have the characteristics of L3 acute lymphoblastic leukaemia (ALL), as described by the French-American-British group (although it should be noted that, in the World Health Organization classification, Burkitt lymphoma is classified as NHL, not as ALL).

The cell population in Burkitt lymphoma is characteristically uniform, with indistinct nucleoli, whereas Burkitt-like lymphomas show a greater degree of nuclear pleomorphism and may contain more prominent nucleoli (fig 1). A subset of the Burkitt lymphomas may show plasmacytoid differentiation, a morphological variation that appears unique to AIDS patients. In the plasmacytoid variant, the cells have eccentrically placed nuclei and abundant cytoplasm that contains immunoglobulin.

Burkitt lymphoma occurring in the HIV setting is characterised by multiple genetic lesions, with the relative significance of each in the pathogenesis of this lymphoma unknown. In addition to the translocation involving $M Y C$, point mutations in regulatory regions associated with $M Y C$ and within the TP53 tumour suppressor gene are common. 

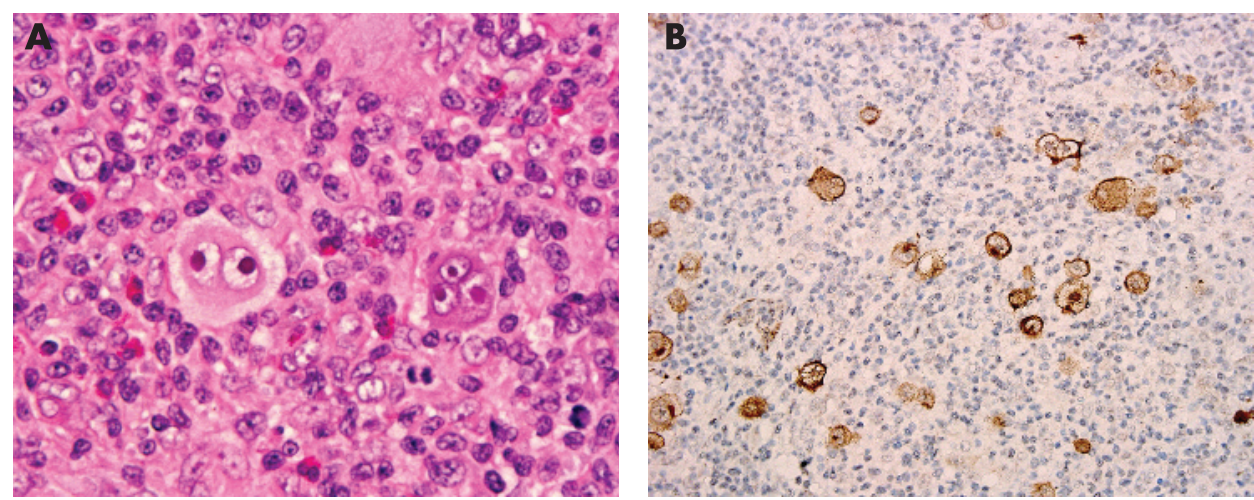

Figure 3 Histology of classical Hodgkin lymphoma in HIV infection. Most cases show features of mixed cellularity subtype with classical Reed-Sternberg cells and polymorphic inflammatory background including eosinophils (A). The vast majority cases are Epstein-Barr virus (EBV) positive as shown with EBV-LMP-1 staining (B). Otherwise the Reed-Sternberg cells show classical phenotype expressing CD30 (C) and CD15 (D).
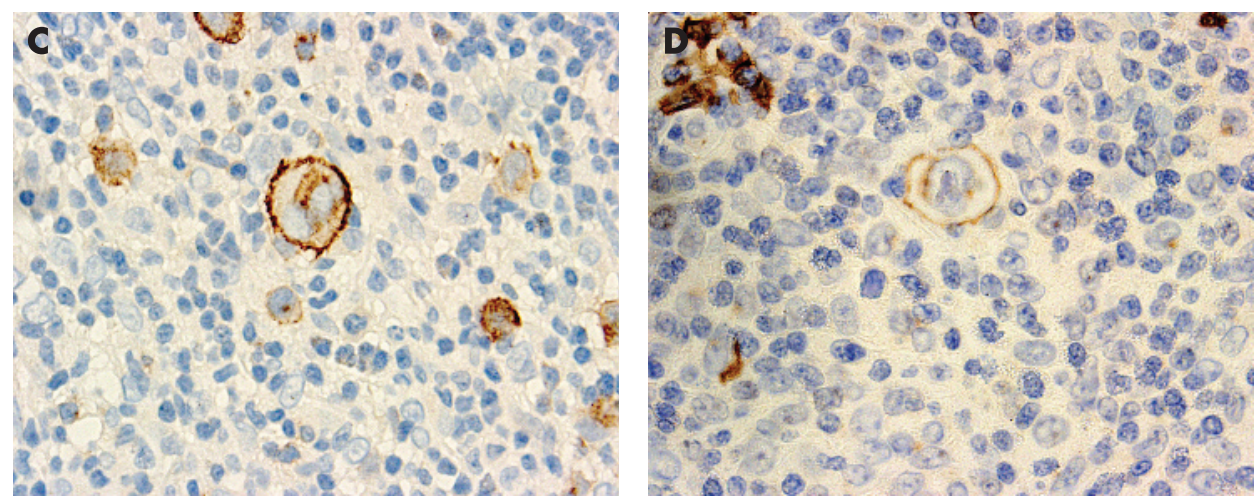

In the context of HIV infection, EBV-encoded RNA (EBER) can be detected by in situ hybridisation in tumour cells in about $30 \%$ of Burkitt lymphomas, $50-70 \%$ of Burkitt lymphomas with plasmacytoid differentiation, and $30-50 \%$ of Burkitt-like lymphomas. Similarly to sporadic or epidemic forms of Burkitt lymphoma, in HIV-associated EBER-positive disease the viral oncogenes LMP-1 and EBNA-2 are not expressed. This is in contrast to EBER-positive immunoblastic DLBCL and PEL, which do show expression of these EBV-associated viral oncogenes. Thus EBV may not play the same role in oncogenesis in these different types of lymphoma.

It is interesting to note that although Burkitt lymphoma is common in HIV-infected patients, it is not associated with other forms of immunosuppression. This may indicate that the oncogenic properties of HIV itself play a greater role in pathogenesis in this highly proliferative tumour compared with EBV or that there are other mechanisms. Dysregulation of cell cycle proteins has been implicated in the development of Burkitt lymphoma. Inactivating mutations of the tumour suppressor gene $R B L 2(\mathrm{Rb} 2 / \mathrm{pl} 30)$ are frequently found in endemic Burkitt lymphoma, and are also found in sporadic cases. By contrast, in HIV-associated cases, abnormal overexpression of wild-type RBL2 is seen. This finding, in conjunction with studies indicating that the function of $\mathrm{Rb} 2 / \mathrm{p} 130$ in the control of the G0/Gl transition can be negated by physical interaction with the Tat protein of HIV-1, may suggest a direct role for HIV proteins acting synergistically with MYC activation in the pathogenesis of Burkitt lymphoma. ${ }^{17}$

\section{Diffuse large B-cell lymphoma}

HIV-associated diffuse large B-cell lymphomas can involve lymph nodes, or present in virtually any extranodal site. The brain is the most common extranodal site, with primary CNS lymphomas accounting for $15-30 \%$ of HIV-associated NHL lymphomas. These neoplasms occur most frequently in the cerebrum as multiple lesions, but can also involve the cerebellum, basal ganglia or brain stem. The lymphoma cells are distributed as perivascular cuffs, with frequent necrosis.
Other frequently involved extranodal sites in HIV-infected patients include the gastrointestinal tract, liver and bone marrow.

As in the HIV-negative setting, the category of HIVassociated DLBCL is a clinically and pathologically heterogeneous group. These lymphomas show a morphological spectrum similar to that seen in the absence of HIV infection, with a diffuse infiltrate of cells with large nuclei, vesicular chromatin, and often prominent nucleoli (fig 1). The cell population consists of a variable mixture of centroblastic cells characterised by irregular nuclear contours, and one to several nucleoli closely associated with the nuclear membrane, and immunoblastic/plasmablastic cells characterised by round to oval nuclear contours and large, centrally located nucleoli (fig 2). Plasmablastic cytological features can also be present, with cells possessing abundant basophilic cytoplasm and eccentrically located nuclei. Lymphomas with a predominance of centroblasts have been termed centroblastic DLBCL, whereas those with greater than $90 \%$ immunoblasts/plasmablasts have been termed immunoblastic DLBCL.

These two general morphological subtypes show correlation with certain clinical features and molecular profiles. The subtypes occur with approximate equal frequency in HIVinfected patients, with the relative frequency of centroblastic DLBCL increasing and that of immunoblastic DLBCL decreasing in recent years due to advances in HIV therapy, specifically the receipt of HAART by eligible patients (see above). Centroblastic DLBCL occurs in the setting of mild immunosuppression, has a low frequency of EBV positivity (30-40\%) without expression of LMP-1, shows a germinal centre B-cell phenotype (expression of CDI0 and BCL6, and lack of expression of CD138 and MUM1), and frequently shows rearrangements of the BCL6 gene. In contrast, immunoblastic DLBCL usually occurs in the context of severe immunosuppression, has a high frequency of EBV positivity (80-90\%) with frequent expression of LMP-1 and EBNA-2, shows a non-germinal centre B-cell/activated Bcell phenotype (lack of expression of CDI0 and BCL6, 

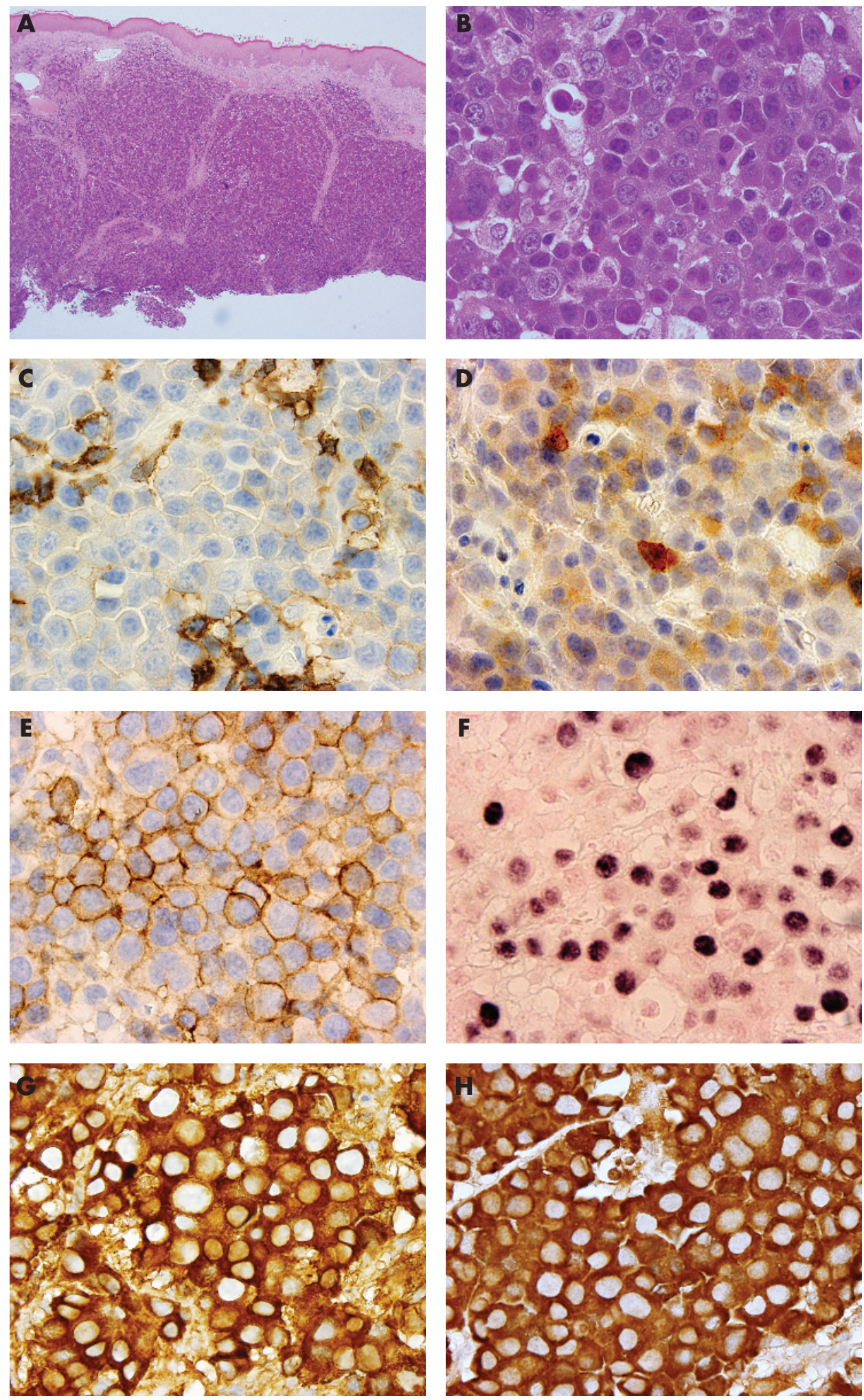

Figure 4 Plasmablastic lymphoma of oral cavity type in HIV infection. The neoplasm typically presents as mucosal masses (A) composed of intermediate-large sized cells with round eccentrically located nuclei with one two large nucleoli (B). The cytoplasm is basophilic and a paranuclear hof may be apparent (B). The tumour cells are often negative for CD45 (C) and CD20, but may show weak variable expression of CD79a (D), and are often positive for plasma cell markers such as CD138, VS38c and CD38 (E). Most cases are positive for Epstein-Barr virus by in situ hybridisation for EBVencoded RNA (F). Typically the plasmablasts contain abundant cytoplasmic immunoglobulin, this case showing expression of $\lg A(G)$ and kappa light chain (H). expression of CD138 and MUM1), and lacks rearrangements of $B C L 6$. Primary CNS lymphomas usually represent the immunoblastic variant of DLBCL.

Recently, gene and protein expression profiling studies have identified at least three subgroups within the heterogeneous category of DLBCL that correlate with prognosis. These subgroups are a germinal centre profile, an activated B-cell profile, and "type 3" profile. ${ }^{21-24}$ A few studies have made early attempts to compare HIV-associated DLBCL with these studies in immunocompetent patients. In a study using tissue microarrays, two dimensional contour-frequency plots constructed from immunohistochemical expression summation scores showed two distinct clusters in non-HIV-associated DLBCL cases, corresponding to a high germinal centre phenotype and a high activated B-cell phenotype. By contrast, the HIV-associated DLBCL cases showed a single cluster on the contour plot, that had an intermediate germinal centre/activated B-cell phenotype..$^{25}$ This preliminary data may reflect that although 
there are morphological similarities between DLBCL subtypes in HIV-infected and uninfected patients, there are distinct differences in the underlying pathogenesis.

\section{Low grade B-cell lymphoma}

Epidemiological studies have indicated that HIV-infected individuals may have a slightly increased incidence of low grade non-Hodgkin lymphoma compared to the general population, estimated as a 14-fold increased risk among HIVinfected patients previously diagnosed with an AIDS-defining illness. ${ }^{26}$ These indolent B-cell lymphomas represent 3-7\% of HIV-associated lymphomas. ${ }^{27-29}$ Reported subtypes have included follicular lymphoma, B-cell small lymphocytic lymphoma, extranodal marginal zone B-cell lymphoma of mucosaassociated lymphoid tissue, and monocytoid B-cell lymphoma. ${ }^{28}$ 30-34 The low grade lymphomas tend to occur in patients with relatively normal peripheral blood CD4 counts, and patients appear to have a similar median survival to that of HIV-negative patients with these types of lymphoma. ${ }^{28}$

\section{Peripheral T-cell lymphoma}

Although not established as an AIDS-defining illness, peripheral T-cell lymphomas constitute another rare type of HIVassociated lymphomas. Studies have estimated a 15-fold increased risk of T-cell neoplasms in HIV-infected persons compared to the expected incidence in the general population. ${ }^{35}$ Reported cases have included a diversity of subtypes, including peripheral T-cell lymphoma, unspecified, anaplastic large cell lymphoma, angioimmunoblastic T-cell lymphoma, enteropathy-type T-cell lymphoma, adult T-cell leukaemia/lymphoma associated with HTLV-I infection, and extranodal NK/T-cell lymphoma. ${ }^{35-39}$ The majority of cases have demonstrated a CD4positive phenotype, with only a few reported instances of a cytotoxic CD8-positive phenotype. ${ }^{36} 384041$ A subset of the cases have been associated with $\mathrm{EBV},{ }^{3641}$ and in one case clonal integration of the HIV genome itself into the tumour cell DNA was shown by Southern blot analysis. ${ }^{14}$

Rarely, patients with advanced HIV infection present with a massive CD8-positive cutaneous T-cell infiltrate that mimics a T-cell lymphoma. These patients typically present with a pruritic, persistent, generalised, papular eruption which may mimic mycosis fungoides. The infiltrating lymphocytes show pleomorphic morphology, involving the dermis and subcutis, with occasional epidermotropism..$^{43}$ These infiltrates most often show polyclonal TCR rearrangements by molecular genetic analysis, consistent with a reactive process. This may reflect a specific immune response to the HIV infection, as the T cells have been shown to have MHC class I restricted cytotoxicity against HIV proteins. ${ }^{44}$ Occasional reports have described the development of clonal T-cell neoplasms in the setting of these atypical infiltrates. ${ }^{45} 46$

\section{Classical Hodgkin lymphoma}

HIV infection increases the risk of HL. ${ }^{11}$ The morphological patterns are similar to those seen in patients without HIV infection, although with a greater proportion of the subtypes (mixed cellularity, lymphocyte depleted) with less favourable prognosis compared to the general population. ${ }^{11}{ }^{47}$ As noted above, the greater proportion of mixed cellularity and lymphocyte depleted subtypes appears specifically related to severe immunocompromise in HIV, while HIV-infected patients with modest immunocompromise are more at risk for the development of the nodular sclerosis subtype. The composition of the reactive inflammatory infiltrate in HIV-associated HL is often characterised by a predominance of CD8-positive T lymphocytes over CD4-positive lymphocytes, by contrast with the background in HL without HIV infection. ${ }^{47}$ This finding may simply reflect the depleted peripheral CD4 counts in this patient population.

The cytological and phenotypic features of the Hodgkin Reed-Sternberg (HRS) cells in HIV-associated HL are similar to those in non-HIV associated HL (fig 3). The HRS cells typically express CD15 and CD30, express CD20 in a minor subset, and lack expression of $\mathrm{CD} 45 .{ }^{47}$ In the vast majority of HIVassociated HL there is coincident EBV infection, with nearly all cases showing EBER and LMP-1 expression in the HRS cells. ${ }^{47}$ This association with EBV is considerably stronger than that seen in HL in the non-HIV infected population.

HIV-associated HL most often presents at an advanced clinical stage, with B symptoms, frequent extranodal disease, and an aggressive course. ${ }^{114}$ Unusual extranodal sites, such as the skin, lung and gastrointestinal tract may be involved. ${ }^{47} 48$ These sites are essentially never involved by HL that is not associated with HIV.

\section{Primary effusion lymphoma}

PEL is a distinct clinicopathological entity occurring almost exclusively in HIV-infected patients. This lymphoma subtype comprises less than 5\% of all HIV-associated NHL. Cases of this type were first described by Knowles et al in $1989,{ }^{49}$ but its distinctive features were not fully recognised until after the identification of the Kaposi sarcoma-associated herpesvirus/ human herpesvirus 8 (KSHV/HHV8) in 1994..$^{50-52}$

PEL consists of a neoplasm of B-cell lineage that typically presents as a pleural, peritoneal or pericardial effusion, usually without a contiguous tumour mass, which is consistently associated with KSHV/HHV8 infection. ${ }^{1}$ The tumour cells have large round to irregular nuclei with prominent nucleoli, and abundant deeply basophilic and occasionally vacuolated cytoplasm; these are described as immunoblastic/plasmablastic or anaplastic morphological features. ${ }^{1}$ Results of recent studies have broadened the scope of PEL to include those presenting as a solid tumour mass with or without an associated effusion. ${ }^{53-55}$ The so-called "extracavitary" or "solid variant" of PEL most commonly involves the gastrointestinal tract or soft tissue, but can also involve lymph nodes. ${ }^{53-55}$ Some studies have suggested that the extracavitary variant of PEL has a slightly better prognosis when compared with cases presenting with effusion. ${ }^{53-55}$

The immunophenotypic features of PEL often make it difficult to confirm B-cell lineage, as the neoplasm usually lacks expression of most B-cell associated antigens including CD19, CD20, CD79a and immunoglobulins. The most frequently expressed antigens include those associated with activation or plasmacytic differentiation, such as CD30, CD45, EMA, CD71, MUM1, and CD138. ${ }^{149}{ }^{50}$ Aberrant expression of Tcell associated antigens CD3 and CD7 has been reported. ${ }^{56-59}$ All cases show positivity for HHV8/KSHV-associated latent nuclear antigen (LNAl) demonstrated by immunohistochemistry. ${ }^{53}$ The presence of EBV coinfection can be demonstrated in most cases by in situ hybridisation for EBER; however, the viral oncoprotein LMP-1 is generally not expressed. ${ }^{1} 4954$

Studies of immunoglobulin genes in PEL show clonal rearrangement and frequent mutations, consistent with a post-germinal centre B-cell neoplasm..$^{41^{51}}$ Gene expression studies on PEL have shown a profile with features of both immunoblasts and plasma cells, clearly distinct from that of other NHL and from germinal centre and memory B cells. ${ }^{61}$ Rarely, clonal rearrangement of T-cell receptor genes has also been demonstrated, although true cases of T-cell lineage PEL are considered extremely rare. ${ }^{62} 63$

PEL may occur preceding or subsequent to other HHV8associated diseases, including multicentric Castleman disease (MCD) and Kaposi sarcoma. ${ }^{57}{ }^{64}$ An HIV-infected patient with recurrent, self-healing monoclonal HHV8 and EBV-positive 
plasmablastic cutaneous infiltrates that followed an indolent clinical course has also been reported..$^{65}$ These "precursor" lesions suggest that additional genetic alterations are necessary for evolution to PEL or other HHV8-positive plasmablastic lymphomas. This hypothesis is supported by cytogenetic studies of PEL that have shown numerous structural and numerical chromosomal abnormalities. ${ }^{66}$ Recurring abnormalities include trisomy 12, trisomy 7, aberrations in 1q21-25, and mutations involving the $5^{\prime}$ non-coding region of the BCL6 gene. ${ }^{66}$ No rearrangements involving $B C L 1, B C L 2, B C L 6$ or $M Y C$ have been identified. ${ }^{54}$

\section{Evolving disease entities associated with HIV infection} Recent literature has suggested new subtypes of HHV8associated lymphoproliferative disorders distinct from PEL, including plasmablastic lymphoma associated with MCD, and germinotropic lymphoproliferative disorder. By contrast with PEL, the neoplastic cells of plasmablastic lymphoma associated with MCD are not coinfected with EBV. ${ }^{64}$ In germinotropic lymphoproliferative disorder, the plasmablasts contain clonally integrated EBV and HHV8 DNA, but are localised within germinal centres.$^{67}$ The clinical features also contrast with those of PEL, as patients have a more indolent disease course. ${ }^{67}$ Additional studies are necessary to further define these disease entities and to better distinguish them from PEL.

\section{Plasmablastic lymphoma of the oral cavity type}

Plasmablastic lymphoma is a distinct type of diffuse large B-cell lymphoma that occurs most often in the oral cavity or jaw of HIV-infected individuals. ${ }^{168}$ This rare lymphoma subtype accounts for $2.6 \%$ of HIV-related NHL. ${ }^{69}$ The first description designated this tumour as a lymphoma of the oral cavity ${ }^{68}$; however, subsequent reports have described less frequent involvement of extraoral sites such as the anal cavity, gastrointestinal tract, lung, paranasal sinus, skin, spermatic cord, testicle, bone and lymph nodes. ${ }^{70-76}$

Regardless of the site of occurrence, plasmablastic lymphoma shows similar morphological and phenotypic features. The neoplastic cells are intermediate to large in size, with round nuclear contours and occasional multinucleation (fig 4). Plasmacytic differentiation is usually apparent, with a cytological spectrum including a minor population of small plasmacytoid cells with condensed chromatin ranging to large cells with dispersed chromatin, prominent central nucleoli and abundant basophilic cytoplasm with a paranuclear hof. ${ }^{1} 686973$ The neoplastic population generally expresses CD45 and plasmacytic markers such as CD138, EMA and MUMl, and usually lacks expression of pan-B-cell antigens such as CD20 and PAX5. ${ }^{169}{ }^{73}$ In early reports, slightly more than $50 \%$ of cases were EBER positive as shown by in situ hybridisation studies ${ }^{68}$; in more recent series all cases of plasmablastic lymphoma have been shown to be EBER positive. ${ }^{69} 73$ EBER-positive cases generally lack expression of EBNA2 and LMP- $1 .{ }^{73}$ HHV 8 infection is not implicated in the pathogenesis of plasmablastic lymphoma, with all cases negative for LNAl when tested by immunohistochemistry. ${ }^{69} 73$ While there is morphological and phenotypic overlap with anaplastic myeloma, extramedullary presentation and frequent EBV infection are distinctive features.

\section{Polymorphic B-cell lymphoma (PTLD-like)}

HIV infection results in a reduction of T-cell immunity similar to that iatrogenically induced in transplant patients. Therefore it is not surprising that polymorphic lymphoid proliferations resembling post-transplant lymphoproliferative disorders (PTLD) have been reported in HIV-infected adults and children. Histologically, these lymphoid proliferations have a variable composition that includes small lymphocytes, ${ }^{77}$ plasma cells,

\section{Take-home messages}

- HIV infection is associated with a significantly increased risk for malignant lymphoma.

- The majority of HIV-associated lymphomas are aggressive B cell neoplasms that also occur in immunocompetent patients.

- Opportunistic infection with lymphotropic herpes viruses contributes to the pathogenesis of lymphoma subtypes more unique to HIV positive patients.

- In HIV-infected patients, the risk of lymphomas has decreased and the clinical outcome improved with highly active antiretroviral therapy.

histiocytes and atypical immunoblasts often with plasmacytoid or Reed-Sternberg-like cytological features. ${ }^{77-80}$ Similarly to PTLD, these infiltrates are often associated with EBV infection. By contrast with HIV-associated lymphoma, these polymorphic infiltrates often show more limited disease distribution, lack oncogene and tumour suppressor gene alterations, and may be polyclonal or show a minor B-cell clone in a polyclonal background. Regression of polymorphic B-cell lymphoma in an HIV-infected patient after anti-retroviral therapy has been reported..$^{78}$

\section{Authors' affiliations}

K L Grogg, A Dogan, Department of Laboratory Medicine and Pathology, Mayo Clinic, Rochester, Minnesota, USA

R F Miller, Centre for Sexual Health and HIV Research, Department of Population Sciences and Primary Care, University College London, and Department of Infectious and Tropical Diseases, London School of Hygiene and Tropical Medicine, London, UK

Competing interests: None declared.

\section{REFERENCES}

1 Raphael M, Borisch B, Jaffe E. Lymphomas associated with infection by the human immune deficiency virus (HIV). In: Jaffe E, Harris N, Stein H, Vardiman J, eds. World Health Organization classification of tumours, pathology and genetics of tumours of haematopoietic and lymphoid tissues. Lyon, France: IARC Press, 2001:260-3.

2 Biggar R, Curtis R, Cote T, et al. Risk of other cancers following Kaposi's relation to acquired immunodeficiency syndrome. Am J Epidemiol 1994;139:362-8.

3 Rabkin C. Epidemiology of AIDS-related malignancies. Curr Opin Oncol 1994;6:492-6.

4 Berel V, Peterman T, Berkelman R, et al. AIDS-associated non-Hodgkin's lymphoma. Lancet 1991;337:805-9.

5 Wilde J, Lee C, Darby S, et al. The incidence of lymphoma in the UK haemophilia population between 1978 and 1999. AIDS 2002;16:1803-7.

6 Diamond C, Taylor T, Aboumrad T, et al. Changes in acquired immunodeficiency syndrome-related non-Hodgkin lymphoma in the era of highly active antiretroviral therapy. Cancer 2006;106:128-35.

7 Besson C, Goubar A, Gabarre J, et al. Changes in AIDS-related lymphoma since the era of highly active antiretroviral therapy. Blood 2001;98:2339-44.

8 Grulich A, Li Y, McDonald A, et al. Decreasing rates of Kaposi's sarcoma and non-Hodgkin's lymphoma in the era of potent combination anti-retroviral therapy. AIDS 2001;15:629-33.

9 Clarke C. Changing incidence of Kaposi's sarcoma and non-Hodgkin's lymphoma among young men in San Francisco. AIDS 2001;15:1913-5.

10 Appleby P, Beral V, Newton R, et al. Highly active antiretroviral therapy and the incidence of cancer in human immunodeficiency virus-infected adults. J Natl Cancer Inst 2000;92:1823-30.

11 Biggar R, Jaffe E, Goedert J, et al. Hodgkin lymphoma and immunodeficiency in persons with HIV/AIDS. Blood 2006; 108:3786-91.

12 Jarrett R. Viruses and lymphoma/leukaemia. J Pathol 2006;208:176-86.

13 Knowles D. Etiology and pathogenesis of AIDS-related non-Hodgkin's lymphoma. Hematol Oncol Clin N Am 2003;17:785-820.

14 Herndier B, Shiramizu B, Jewett N, et al. Acquired immunodeficiency syndromeassociated T-cell lymphoma: evidence for human immunodeficiency virus type 1 associated T-cell transformation. Blood 1992;79:1768-74.

15 Laurence J, Astrin S. Human immunodeficiency virus induction of malignant transformation in human B lymphocytes. Proc Natl Acad Sci 1991;88:7635-9. 
16 Kundu R, Sangiorgi F, Wu L-Y, et al. Expression of the human immunodeficiency virus-Tat gene in lymphoid tissues of transgenic mice is associated with B-cell lymphoma. Blood 1999;94:275-82.

17 Bellan C, Lazzi S, DeFalco G, et al. Burkitt's lymphoma: new insights into molecular pathogenesis. J Clin Pathol 2003;56:188-93.

18 Piriou $\mathbf{E}$, van Dort K, Nanlohy N, et al. Loss of EBNA 1-specific memory CD4+ and CD8+ T cells in HIV-infected patients progressing to AIDS-related nonHodgkin lymphoma. Blood 2005; 106:3166-74.

19 Spina M, Tirelli U, Zagonel V, et al. Burkitt's lymphoma in adults with and without human immunodeficiency virus infection. Cancer 1998;82:766-74.

20 Gold J, Castella A, Zalusky R. B-cell acute lymphocytic leukemia in HIV-antibodypositive patients. Am J Hematol 1989:32:200-4.

21 Rosenwald A, Wright G, Chan W, et al. The use of molecular profiling to predict survival after chemotherapy for diffuse large-B-cell lymphoma. N Engl J Med 2002;346: 1937-47.

22 Chang C, McClintock S, Cleveland R, et al. Immunohistochemical expression patterns of germinal center and activation B-cell markers correlate with prognosis in diffuse large B-cell lymphoma. Am J Surg Pathol 2004;28:464-70.

23 Alizadeh A, Eisen M, Davis $R$, et al. Distinct types of diffuse large B-cell lymphoma identified by gene expression profiling. Nature 2000;403:503-11.

24 Hans C, Weisenburger D, Greiner T, et al. Confirmation of the molecular classification of diffuse large B-cell lymphoma by immunohistochemistry using a tissue microarray. Blood 2004; 103:275-82.

25 Madan R, Gormley R, Dulau A, et al. AIDS and non-AIDS diffuse large B cell lymphomas express different antigen profiles. Mod Pathol 2006;19:438-46.

26 Cote T, Biggar R, Rosenberg P, et al. Non-Hodgkin's lymphoma among people with AIDS: incidence, presentation, and public health burden. Int J Cancer 1997;73:645-50

27 Ziegler J, Beckstead J, Volberding P, et al. Non-Hodgkin's lymphoma in 90 homosexual men: relation to generalized lymphadenopathy and the acquired immunodeficiency syndrome. N Engl J Med 1984;311:565-70.

28 Levine A, Sadeghi S, Espina B, et al. Characteristics of indolent non-Hodgkin lymphoma in patients with type 1 human immunodeficiency virus infection. Cancer 2002;94:1500-6.

29 Lowenthal D, Straus D, Campbell S, et al. AIDS-related lymphoid neoplasia: the Memorial Hospital experience. Cancer 1988;61:2325-37.

30 Rodriguez-Sanjuan J, Echevarria S, Alvarez-Canas C. Primary gastric lymphoma in an HIV-infected patient. J Acquir Immune Defic Syndr Human Retrovirol 1996:13:467-8.

31 Wotherspoon A, Diss T, Pan L, et al. Low grade gastric B-cell lymphoma of mucosa associated lymphoid tissue in immunocompromised patients. Histopathology 1996;28:129-34.

32 Teruya-Feldstein J, Temeck B, Sloas $M$, et al. Pulmonary malignant lymphoma of mucosa-associated lymphoid tissue (MALT) arising in a pediatric HIV-positive patient. Am J Surg Pathol 1995;19:357-63.

33 Sundaram K, Singh B, Har-El G. Nasopharyngeal mucosa-associated lymphoid tissue lymphoma in patients infected with human immunodeficiency virus. Am J Otolaryngol 1999;20:56-8

34 Chetty R, Pillay S. Coexistent gastric MALT lymphoma and Kaposi's sarcoma in an HIV positive patient. J Clin Pathol 1999;52:313-6.

35 Biggar R, Engels E, Frisch M, et al. Risk of T-cell lymphomas in persons with AIDS. J Acquir Immune Defic Syndr Human Retrovirol 2001 26:371-6.

36 Cornfield D, Papiez J, Lynch J, et al. Natural killer-like T-cell lymphoma of the parotid in a patient infected with human immunodeficiency virus. Arch Pathol Lab Med 2002; 126:738-41

37 Arber D, Chang K, Weiss L. Peripheral T-cell lymphoma with Touton-like tumor giant cells associated with HIV infection: report of two cases. Am J Surg Pathol 1999;23:519-22

38 Arzoo K, Bu X, Espina B, et al. T-cell lymphoma in HIV-infected patients. J Acquir Immune Defic Syndr 2004;36:1020-7.

39 Collins J, Hernandez A, Hidalgo J, et al. High proportion of T-cell systemic nonHodgkin lymphoma in HIV-infected patients in Lima, Peru. J Acquir Immune Defic Syndr 2005:40:558-64.

40 Ruco L, DiNapoli A, Pilozzi E, et al. Peripheral T cell lymphoma with cytotoxic phenotype: an emerging disease in HIV-infected patients? AIDS Res Hum Retroviruses 2004;20:129-33.

41 Merchant S, Viswanatha D, Zumwalt R, et al. Epstein-Barr virus-associated intravascular large T-cell lymphoma presenting as acute renal failure in a patient with acquired immune deficiency syndrome. Human Pathol 2003:34:950-4.

42 Friedler S, Parisi M, Waldo E, et al. Atypical cutaneous lymphoproliferative disorder in patients with HIV infection. Int J Dermatol 1999;38:111-8.

43 Guitart J, Variakojis D, Kuzel T, et al. Cutaneous CD8+ T cell infiltrates in advanced HIV infection. J Am Acad Dermatol 1999:41:722-7.

44 Bachelez H, Hadida F, Gorochov G. Massive infiltration of the skin by HIVspecific cytotoxic CD8+ T cells. N Engl J Med 1996;335:61-2.

45 Hivnor D, Nguyen V, Rook A, et al. CD8+ lymphoma in a patient with human immunodeficiency virus. Arch Dermatol 2005;141:1321-2.

46 Poisez B, Dube D, Dube S, et al. HTLV-Il-associated cutaneous T-cell lymphoma in a patient with HIV-1 infection. N Engl J Med 2000;342:930-6.

47 Thompson L, Fisher M, Chu W, et al. HIV-associated Hodgkin lymphoma. Am J Clin Pathol 2004; 121:727-38.

48 Doweiko J, Dezube B, Pantanowitz L. Unusual sites of Hodgkin's lymphoma. J Clin Oncol 2004:22:4227-31

49 Knowles D, Inghirami G, Ubriaco A, et al. Molecular genetic analysis of three AIDS-associated neoplasms of uncertain lineage demonstrates their B-cell derivation and the possible pathogenetic role of the Epstein-Barr virus. Blood 1989;73:792-9.
50 Nador R, Cesarman E, Chadburn A, et al. Primary effusion lymphoma: a distinct clinicopathologic entity associated with the Kaposi's sarcoma-associated herpesvirus. Blood 1996;88:645-56.

51 Cesarman E, Chang Y, Moore P, et al. Kaposi's sarcoma-associated herpesviruslike DNA sequences in AIDS-related body-cavity-based lymphomas. N Engl J Med 1995:332:1186-91.

52 Chang $Y$, Cesarman E, MS P, et al. Identification of herpesvirus-like DNA sequences in AIDS-associated Kaposi's sarcoma. Science 1994;266:1865-9.

53 Carbone A, Gloghini A, Vaccher E, et al. Kaposi's sarcoma-associated herpesvirus/human herpesvirus type 8-positive solid lymphomas. J Mol Diagn 2005;7:17-27

54 Chadburn A, Hyjek E, Mathew S, et al. KSHV-positive solid lymphomas represent an extra-cavitary variant of primary effusion lymphoma. Am J Surg Pathol 2004;28:1401-16

55 Deloose S, Smit L, Pals F, et al. High incidence of Kaposi sarcoma-associated herpesvirus infection in HIV-related solid immunoblastic/plasmablastic diffuse large B-cell lymphoma. Leukemia 2005;19:851-5.

56 Boulanger E, Hermine O, Fermand J-P, et al. Human herpesvirus 8 (HHV8)associated peritoneal primary effusion lymphoma (PEL) in two HIV-negative elderly patients. Am J Hematol 2004;76:88-91.

57 Oksenhendler E, Boulanger E, Galicier L, et al. High incidence of Kaposisarcoma-associated herpesvirus-related non-Hodgkin lymphoma in patients with HIV infection and multicentric Castleman disease. Blood 2002:99:2331-6.

58 Said J, Shintaku I, Asou H, et al. Herpesvirus 8 inclusions in primary effusion lymphoma: report of a unique case with T-cell phenotype. Arch Pathol Lab Med $2001 ; 123: 257-60$.

59 Beaty M, Kumar S, Sorbara L, et al. A biphenotypic human herpesvirus 8associated primary bowel lymphoma. Am J Surg Pathol 1997;21:719-24.

60 Carbone A, Gloghini A. AIDS-related lymphomas: from pathogenesis to pathology. Br J Haematol 2005;130:662-70.

61 Klein U, Gloghini A, Gaidano G, et al. Gene expression profile of AIDS-related primary effusion lymphoma (PEL) suggests a plasmablastic derivation and identifies PEL-specific transcripts. Blood 2003;101:4115-21.

62 Lechapt-Zalcman E, Challine D, Delfau-Larue M, et al. Association of primary pleural effusion lymphoma of T-cell origin and human herpesvirus 8 in a human immunodeficiency virus-seronegative man. Arch Pathol Lab Med $2001 ; 125: 1246-8$

63 Coupland S, Charlotte F, Mansour G, et al. HHV-8-associated T-cell lymphoma in a lymph node with concurrent peritoneal effusion in an HIV-positive man. Am J Surg Pathol 2005;29:647-52.

64 Dupin N, Diss T, Kellam P, et al. HHV-8 is associated with a plasmablastic variant of Castleman disease that is linked to HHV-8-positive plasmablastic lymphoma. Blood 2000;95:1406-12.

65 Gilaberte M, Gallardo F, Bellosillo B, et al. Recurrent and self-healing cutaneous monoclonal plasmablastic infiltrates in a patient with AIDS and Kaposi sarcoma. Br J Dermatol 2005;153:828-32.

66 Gaidano G, Capello D, Cilia A, et al. Genetic characterization of HHV-8/KSHV positive primary effusion lymphoma reveals frequent mutations of $B C L 6$ : implications for disease pathogenesis and histogenesis. Genes Chromosomes Cancer 1999;24:16-23.

67 Du $M-Q$, Diss T, Liu $H$, et al. KSHV-and EBV-associated germinotropic lymphoproliferative disorder. Blood 2002;100:3415-8.

68 Delecluse H, Anagnostopoulos I, Dallenbach F, et al. Plasmablastic lymphomas of the oral cavity: a new entity associated with the human immunodeficiency virus infection. Blood 1997:89:1413-20.

69 Folk G, Abbondanzo S, Childers E, et al. Plasmablastic lymphoma: a clinicopathologic correlation. Ann Diagn Pathol 2006;10:8-12.

70 Tavora F, Gonzalez-Cuyar L, Chen-Chih J, et al. Extra-oral plasmablastic lymphoma: report of a case and review of literature. Human Pathol 2006;37:1233-6.

71 Schichman S, McClure R, Schaefer R, et al. HIV and plasmablastic lymphoma manifesting in sinus, testicles, and bones: a further expansion of the disease spectrum. Am J Hematol 2004;77:291-5.

72 Chetty R, Hlatswayo N, Muc R, et al. Plasmablastic lymphoma in HIV+ patients: an expanding spectrum. Histopathology 2003:42:605-9.

73 Dong H, Scadden D, de Leval L, et al. Plasmablastic lymphoma in HIV-positive patients: an aggressive Epstein-Barr virus-associated extramedullary plasmacytic neoplasm. Am J Surg Pathol 2005;29:1633-41.

74 Lin $Y$, Rodrigues G, Turner J, et al. Plasmablastic lymphoma of the lung: report of a unique case and review of the literature. Arch Pathol Lab Med 2001;125:282-5.

75 Pruneri G, Graziadei G, Ermellino L, et al. Plasmablastic lymphoma of the stomach. Haematologica 1998:83:87-9.

76 Hausermann P, Khanna N, Buess $M$, et al. Cutaneous plasmablastic lymphoma in an HIV-positive male: an unrecognized cutaneous manifestation. Dermatology 2004; 208:287-90.

77 Nador R, Chadburn A, Gundappa G, et al. Human immunodeficiency virus (HIV)-associated polymorphic lymphoproliferative disorders. Am J Surg Pathol 2003;27:293-302

78 Martin S, Zukerberg L, Robbins G. Reactive Epstein-Barr virus-related polyclonal lymphoproliferative disorder in a patient with AIDS. Clin Infect Dis 2005;41:e76-9

79 Shiramizu B, Herndier B, Meeker T, et al. Molecular and immunophenotypic characterization of AIDS-associated, Epstein-Barr virus-negative, polyclonal lymphoma. J Clin Oncol 1992;10:383-9.

80 Tao J, Valderrama E. Epstein-Barr virus-associated polymorphic B-cell lymphoproliferative disorders in the lungs of children with AIDS: a report of two cases. Am J Surg Pathol 1999;23:560-6. 